\title{
A DIEZ AÑOS DEL GOLPE DE ESTADO EN HONDURAS: ENTRE LAS NARRATIVAS DE LA “TRANSICIÓN A LA DEMOCRACIA" Y LA INSTAURACIÓN DEL PROYECTO NEOLIBERAL EN CENTROAMÉRICA
}

\author{
TEN YEARS AFTER THE COUP D'ÉTAT: RUPTURE OF A POPULAR \\ NATIONAL PROCESS AND SECURITY OF THE RIGHT IN HONDURAS
}

\author{
Génesis Guzmán Padilla \\ Andrés León Araya
}

Recibido: 31/05/2019 - Aceptado: 21/08/2019

\begin{abstract}
Resumen
Después de diez años, mucho se ha escrito y reflexionado sobre el golpe de Estado en Honduras del 2009 y sus efectos, tanto a nivel doméstico, como de las dinámicas geopolíticas a nivel Centro y Latinoamericano. Sin embargo, en su mayoría, los y las analistas se han decantado por acercamientos que enfatizan elementos institucionales, de cultura política y captura de Estado, combinada con una mirada poco atenta a la historia hondureña y a los procesos que llevaron a que la expulsión forzada de Manuel Zelaya Rosales se volviera una alternativa viable. Para ir más allá de este acercamiento, proponemos ver el golpe de Estado como parte del proceso de instauración del proyecto neoliberal en Honduras y los procesos de formación de clase y Estado que lo han acompañado.
\end{abstract}

Palabras clave: Golpe de Estado, Honduras, Neoliberalismo, Centroamérica, transitología.

\begin{abstract}
After 10 years, much has been written about the 2009 coup d'état in Honduras and its effects, both domestically and in relation to the regional geopolitics of Central and Latin America. However, most analysts have favored approaches that focus on institutional, political culture and state capture aspects of the conflict, while paying little attention to the Honduran history and the processes that created the conditions of possibility for the ousting of Manuel Zelaya Rosales. To go beyond these shortcomings, we propose an approach to the coup d'état that understands it as part of the process of implementation of the neoliberal project in Honduras, and the accompanying processes of state and class formation.
\end{abstract}

Keywords: Coup d'état, Honduras, Central America, neoliberalism, transitology. 


\section{Introducción}

El 28 de junio del 2009, entre las 5 y las 6 de la mañana el juez ejecutor, teniente coronel René Antonio Hepburn Bueso, acompañado por un comando especial del ejército hondureño, procedió a hacer efectiva la orden de captura de José Manuel Zelaya Rosales, hasta ese momento presidente constitucional de Honduras. Ese día se tenía planificado llevar a cabo una encuesta a nivel nacional para consultarle a la ciudadanía hondureña su opinión sobre una posible y futra convocatoria a una asamblea nacional constituyente. Como sabemos, al final dicha encuesta no se llevó a cabo y "siguiendo el patrón establecido por el Golpe de Estado del 3 de octubre de 1963 que derribó al doctor Ramón Villeda Morales y el golpe de barracas del 30 de marzo de 1984 que defenestró al hasta entonces todopoderoso General Gustavo Álvarez Martínez, Zelaya Rosales fue expulsado del país y llevado a Costa Rica" (Salgado 11).

Después de diez años, mucho se ha escrito y reflexionado sobre el golpe de Estado

y sus efectos, tanto a nivel doméstico, como de las dinámicas geopolíticas en el ámbito Centro y Latinoamericano. Sin embargo, en su mayoría, las personas analistas se han decantado por acercamientos que privilegian los temas institucionales, de cultura política, captura de Estado y conflicto interélites, al mismo tiempo que presentan poco en la historia hondureña y en los procesos que llevaron a que la expulsión forzada del presidente electo se volviera una alternativa viable. Con esto en mente, el presente artículo se divide en tres partes: en la primera, se hace una muy breve caracterización de las explicaciones más comunes que se han dado del golpe. A continuación, se plantea que la narrativa dominante dentro de estos estudios es similar a la de la "transición a la democracia" y que, por tanto, adolecen de muchas de las mismas limitaciones: una visión restringida y normativa de la democracia y con poca atención a los procesos de formación de clase y Estado. Finalmente, proponemos algunas claves de lectura para reinterpretar lo que estaba en juego con la expulsión de Zelaya Rosales, a partir de una caracterización general del proceso de instauración del proyecto neoliberal y de las reacciones de los grupos subalternos.

\section{Las miradas sobre el golpe: Diseño institucional, cultura política y conflicto interélite}

En general ubicamos tres formas dominantes en las que ha sido analizado el golpe de Estado en Honduras. Una primera lectura ve la expulsión de Zelaya como un drama nacional, que debe ser entendido en un marco regional más amplio, definido por la disputa geopolítica entre EE. UU. y Venezuela y el supuesto avance de la izquierda electoral en varios países de América Latina (Brasil, Argentina, Venezuela, Uruguay, Paraguay, Bolivia, Ecuador, Nicaragua) (Alcántara Sáez; Benítez; Feeley; Purper; Ruhl; Treminio Sánchez). Desde esta perspectiva, el golpe de Estado era parte de un esfuerzo por detener dicho avance. Un aspecto que llama la atención de esta perspectiva es la influencia que parece tener la teoría del "dominó" que fue utilizada durante la 
Guerra Fría por el presidente estadounidense Dwight Eisenhower para explicar la amenaza del comunismo en el mundo. De acuerdo con esta visión, existía el peligro de que las ideas comunistas se expandieran por contagio, si no se detenía su avance (Leeson y Dean). Para nuestro caso, la cercanía de Zelaya con el régimen bolivariano de Chávez y el proyecto del Alba (Alianza para las Américas) era una clara señal de su viraje hacia la izquierda. Más aún, su propuesta de la Cuarta Urna ${ }^{1}$ es vista como un claro ejemplo de que estaba intentando repetir los pasos del presidente venezolano, legalizar la reelección y perpetuarse en el poder. Esta situación generaba incertidumbre e inestabilidad que debía de ser detenida antes de que se expandiera más (Borón; Gordon y Webber; Llanos y Marsteintredet; Pine; Salomón).

Una segunda lectura, ve más bien en el golpe de Estado un claro ejemplo de la política injerencista e imperialista de los Estados Unidos en América Latina. Desde esta perspectiva, es evidente que, si bien el golpe es llevado a cabo por fuerzas domésticas, las condiciones de posibilidad estaban dadas por la aprobación y apoyo de potencias regionales como los EE. UU., más allá de la censura inicial presentada por el presidente Obama y su secretaria de Estado, Hillary Clinton, y Canadá. Así, detrás de la expulsión de Zelaya estaba el interés por detener su acercamiento a ciertos sectores sociales y las propuestas de reforma política y social que estaban desarrollando, así como proteger los intereses de sus empresas en sectores claves como la minería y la industria maquiladora (Castro Suárez; Frank; Phillips; Shipley, 2017).

En su conjunto, estas dos líneas argumentativas exponen al golpe de Estado como un drama regional, donde las disputas geopolíticas y supuestamente ideológicas, entre Venezuela -como representante de la "nueva" izquierda latinoamericana-y los Estados Unidos, se jugaron en distintos escenarios internacionales (como la ONU y la OEA), y domésticos (el Congreso Nacional Hondureño, la Corte Suprema de Justicia). Sin embargo, con muy pocas excepciones, no se les ha dedicado mayor atención a las particularidades históricas de las fuerzas en contienda a nivel doméstico.

Por último, tenemos un conjunto de estudios que también se estructuran alrededor de la narrativa de la transición democrática, pero que le suman también los efectos que ha tenido la "otra transición" que ha sufrido la región centroamericana desde los 1990: del ajuste estructural o del neoliberalismo (Martí i Puig y Sánchez-Ancochea). Dentro de este conjunto, se plantea que existe una contradicción entre la propuesta de la transición democrática, con las políticas y lógicas económicas del país, que más bien han llevado a un estancamiento o deterioro de las condiciones de vida de la población hondureña. Esto es el resultado de la actitud rapaz de las élites económicas y políticas nacionales, que se han aprovechado de esta doble transición para enquistarse aún más dentro del tejido del Estado con una lógica patrimonial y clientelista, donde lo público se ha vuelto un botín para ser saqueado. Así, se hace un balance, donde se ha avanzado en términos de los derechos ciudadanos individuales, pero ha habido un retroceso en términos de derechos económicos (Aguilar; Barrachina Lisón; Pérez-Sáinz; Soler). 


\section{La transición a la democracia como proyecto de clase}

En la sección anterior planteamos que existen paralelismos entre la discusión sobre lo que ha sido denominado la "transitología" (Vitullo), y las explicaciones que se dan sobre el golpe de Estado en Honduras. La idea de las transiciones democráticas no es nueva, ni basada específicamente en la experiencia centroamericana. Se trata más bien de un acercamiento a la pregunta sobre la transformación de las sociedades en el marco más amplio de la expansión de la modernidad, que se volvió dominante dentro de las ciencias sociales, particularmente las estadounidenses, hacia finales de la década de los 1980 (Gallardo; Robinson, 1996). Dicha tradición académica ha tenido una influencia significativa en las formas en que se ha pensado a la región latinoamericana en general, y a la centroamericana en específico, durante el período posterior a la Guerra Fría y la caída del muro de Berlín, el ascenso de la así denominada "globalización" y el inicio de lo que Francis Fukuyama ha denominado como el "fin de la historia".

Para este politólogo estadounidense, lo que se estaba viviendo en el mundo hacia finales del siglo veinte era:

No solo el fin de la Guerra Fría, o el paso de un período particular de la historia de la postguerra, sino el fin de la historia como tal: es decir, el punto final de la evolución ideológica humana y la universalización de la democracia occidental liberal como la forma final de gobierno humano (3).

El resultado de este fin de la historia era la liquidación de cualquier forma alternativa de sociedad y, por tanto, a pensar el cambio social y político como una marcha inexorable hacia el liberalismo occidental. Es en este contexto intelectual y político que Samuel Huntington plantearía que, en los 1990, el mundo estaba experimentando una "tercera ola" de democratización, la más grande de la historia. Siguiendo el espíritu de los argumentos presentados por Robert Dahl $(1973,1989)$, bajo sus ideas sobre la "poliarquía", Huntington sostenía la necesidad de redefinir lo que se entiende por democracia, alejándose de argumentos basados en la fuente de la autoridad que sustentan al gobierno democrático, o sobre sus fines morales y políticos. Para él era necesario más bien entender a la democracia en término "empíricos e institucionales", a partir de sus procedimientos, fundamentalmente en el ejercicio competitivo del voto.

Esta articulación entre definiciones basadas en elementos procedimentales y la idea del fin de la historia, es el núcleo central de la gran mayoría de la literatura sobre transiciones democráticas. ${ }^{2}$ Se parte de una temporalidad lineal donde las diferentes sociedades se encuentran en un proceso ascendente de regímenes políticos autoritarios, hacia democracias representativas electorales, con los casos de Estados Unidos y Europa occidental como el modelo a seguir. Así, no solo se trataba de una definición de democracia bastante acotada, sino también normativa donde cualquier 
tendencia que se desviara del modelo presentado, era vista como algo que tiene que ser corregido (Gallardo).

Según William Robinson (1996), el ascenso dentro de la academia estadounidense de la "transitología" había sido el resultado de su promoción activa por parte del gobierno estadounidense, en la forma de financiamiento, becas y la promoción de publicaciones y encuentros. Los intereses detrás de este apoyo no eran estrictamente académicos, sino que eran parte de un cambio en la estrategia de política internacional de los EE. UU. en el mundo: de apoyar dictaduras y regímenes autoritarios alineados con la "doctrina de seguridad nacional" durante la Guerra Fría, a promover la democracia (poliarquía, como la denomina el autor siguiendo a Dahl) durante el período de ascenso del proyecto neoliberal.

Robinson plantea que detrás de las evidentes diferencias que existen entre apoyar regímenes autoritarios y apoyar poliarquías, hay una constante que recorre toda la política internacional de los EE. UU.: mantener un cierto nivel de estabilidad política que permita conservar su posición hegemónica en la región y en el mundo. Durante el período de Guerra Fría y de batalla declarada contra el "comunismo", dicha estabilidad estaba mejor servida con regímenes fuertes y con una importante presencia militar. Sin embargo, con la caída del muro de Berlín, y el paso a un mundo unipolar, las dictaduras militares de seguridad nacional no solo ya no eran necesarias en términos políticos, sino que también venían en detrimento del ascendente proyecto económico neoliberal, orientado hacia la liberalización de las economías nacionales y su creciente articulación con el mercado global. En este caso, la idea de mercados más libres necesita ser acompañada de una ideología y proyecto político compatible, donde la democracia sea representativa liberal, con la centralidad que le da a la idea de libertad, el complemento perfecto.

De acuerdo con Gérard Duménil y Dominique Lévy, el neoliberalismo debe de ser entendido como la estrategia política de un grupo de sectores económicos, vinculados al capital financiero, que buscaban liberar al capital de los compromisos adquiridos con respecto a los sectores trabajadores, en la forma del Estado desarrollista, durante el período Keynesiano o Fordista. Sin embargo, al igual que sucede con el fordismo, es imposible hablar de un solo tipo de neoliberalismo y lo que encontramos más bien es un conjunto de propuestas económicas (y políticas) que plantean la necesidad de liberar a los mercados lo más posible de la regulación estatal, permitiendo que las fuerzas del mercado sean las que definan la mejor manera de distribuir los recursos. Lo paradójico de esta propuesta, nos dirá Andrew Gamble, es que al mismo tiempo que busca liberar a la economía en la medida de lo posible de toda regulación, necesita de Estados fuertes que logren imponer y vigilar dicha "libertad". Así, detrás de la obsesión neoliberal por flexibilizar los mercados y mantener los equilibrios macroeconómicos, encontramos un esfuerzo para transferir la mayor parte de los costos económicos y sociales del Estado a los individuos y mercados. 
Al mismo tiempo, el impulso de este tipo de políticas poco populares trae a colación una de las contradicciones centrales históricas del capitalismo de libre mercado: entre la necesidad de generar ganancias inmediatas y conseguir algún tipo de legitimidad democrática para sobrevivir. Como nos recuerda el mismo Gamble, detrás de las políticas desarrollistas y redistributivas que se impulsaron durante el período Fordista estaba un esfuerzo por asegurar la legitimidad política del capitalismo, en el contexto de la disputa con el bloque soviético. Es en esta línea que la propuesta de la promoción de la poliarquía y de la transición a la democracia se articula con el proyecto neoliberal. Distintos autores han argumentado que la estrategia neoliberal también se expresa en un discurso ideológico que busca transferir la responsabilidad del bienestar al individuo, de lo colectivo o público a lo individual (Harvey; Lazzarato; Rose, O’Malley y Valverde). Así, más que promover políticas redistributivas "costosas" o impulsar medidas impositivas que asfixien a los emprendimientos privados, las políticas estatales deben de concentrarse en fortalecer a las organizaciones de sociedad civil (de beneficencia, por ejemplo) y generar las condiciones para que las personas puedan mejorar su "capital social". Este tipo de propuestas no solo son compatibles con las ideas del libre mercado, sino que también buscan "expiar" de sus culpas a los gobiernos, ya que "si la democracia es limitada a un 'sistema de gobierno', entonces las enormes concentraciones de riqueza y poder en instituciones 'privadas' como las corporaciones transnacionales, no es un tema relevante para la 'democracia'”' (Robinson, 1996, 56).

Es en este punto donde vemos la principal debilidad de la propuesta analítica (y normativa) de la transitología. Al proclamar a la democracia como el mejor y único régimen político deseable, y al equiparar a esta con el modelo de "poliarquía" (Robinson, 1996) que hemos venido caracterizando, solo puede juzgar la pertinencia de acciones y proyectos políticos en relación al "avance" o "retroceso" de la transición democrática, entendida fundamentalmente como un ejercicio procedimental. Así las cosas, historias como la de Honduras desde al menos la década de 1980 es vista como una aplicación truncada o incompleta de la teoría y no como el resultado de la forma que dicha "transición" tomó dentro del proceso geopolítico regional y de disputa entre grupos dominantes y subalternos en el contexto hondureño.

\section{El proyecto neoliberal en Honduras}

Como mencionamos anteriormente, la mayor parte de la literatura sobre el golpe de Estado del 2009, lo ubica como parte del proceso que se abre en los 1980 con la transición a la democracia. Generalmente esta contextualización histórica es utilizada para plantear que el derrocamiento de Zelaya es una muestra de la debilidad y la lógica truncada o pervertida de dicho proceso de transición. Nosotros consideramos más que el golpe de Estado del 2009 debe de ser entendido como el resultado de la forma en que el proyecto neoliberal se impuso y ha tomado forma en Honduras, donde la 
supuesta transición a la democracia es parte de un proceso de transformación económica y política más amplia. Pero también, creemos que para entender el proceso de imposición neoliberal de 1980 y 1990, tenemos que devolvernos algunas décadas más en el tiempo.

El 3 de octubre de 1963, setenta y siete días antes de concluir su mandato, el presidente del Partido Liberal Ramón Villeda Morales fue derrocado por el entonces coronel Oswaldo López Arellano, jefe de las fuerzas armadas. Dicho golpe de Estado venía a dar al traste con un proceso reformista bastante importante, en el cual el gobierno de Villeda Morales había promovido la creación del Código de Trabajo, la Ley de Fomento Industrial y el régimen de seguridad social, así como impulsado el proceso de integración regional centroamericana. Al final, su expulsión estuvo vinculada con los temores que su agenda generaron en los sectores más conservadores del país, pero sobre todo a la más que posible elección del candidato Liberal, Modesto Rodas Alvarado, en las próximas elecciones (Argueta). ${ }^{3}$

El golpe de Estado de 1963 abriría un largo período de control militar sobre el Estado, con intermitentes períodos de gobiernos civiles, que se extendería hasta 1981 cuando se llevaron a cabo las elecciones que dan inicio al período que se conoce como de transición a la democracia. Estos dieciocho años de gobierno militar mostraron cuatro tendencias que son importantes para entender la forma que tomaron las transformaciones de los 1980 y 1990. Primero, la creciente penetración de las relaciones capitalistas en el país en el período de la postguerra, había generado un proceso de concentración de la tierra, particularmente en el sur y el occidente del país, lo que llevaba a un aumento de la conflictividad agraria y la creciente organización campesina (Anderson, 1983; Boyer; Jansen). Al mismo tiempo, este creciente desarrollo capitalista había generado nuevos grupos sociales, como los obreros de las plantaciones bananeras e industrias vinculadas, los cuales mostraban crecientes niveles de combatividad y organización sindical, como había quedado demostrado de forma patente durante la gran Huelga Bananera de 1954 (Barahona, 2005; Euraque, 1996).

Segundo, el gobierno militar respondió a dicha conflictividad con una estrategia marcada por ciclos de represión y reformismo. Por ejemplo, para la década de 1970, particularmente después de 1972, encontramos un período de reformismo castrense cuyo objetivo explícito era la "actualización histórica" del país, mediante el impulso de un conjunto de políticas públicas reformistas las cuales, en muchos casos como el de la reforma agraria, iban mucho más allá de lo que inicialmente propusiera el gobierno de Villeda Morales. Tercero, los ritmos y cambios de estos ciclos entre la represión y el reformismo estaban fundamentalmente marcadas por los intereses y la influencia geopolítica de los EE. UU. en la región: tanto la represión en contra de los grupos subalternos, como la promoción de políticas reformistas (parte de la Alianza para el Progreso) tienen que ser entendidas en el contexto de la Guerra Fría en Centroamérica y los esfuerzos por derrotar la supuesta "amenaza" del comunismo. 
En todo caso, para finales de la década de los 1970 el proyecto político militar hondureño daba claras muestras de desgaste. En términos económicos, el país se encontraba sumido en una grave crisis, con bajas tasas de crecimiento, altos niveles de endeudamiento, de inflación y de pobreza. Socialmente, la conflictividad social, si bien no alcanzaba los niveles de vecinos como Nicaragua o El Salvador, seguía creciendo, tanto en el campo como en las ciudades. A nivel externo, la llegada de Jimmy Carter a la presidencia estadounidense en 1977 se iba a traducir a un cambio dentro de la política extranjera estadounidense: del apoyo incondicional a cualquier régimen que demostrara su talante anticomunista, al impulso de regímenes de democracia representativa (Robinson, 1996).

Sin embargo, al mismo tiempo que se abría este espacio hacia la democratización formal en la región, la Revolución sandinista resultaba triunfadora en Nicaragua (1979) y en El Salvador el conflicto militar entre la guerrilla y el ejército seguía en escalada. Así, por más deseable que fuera la democratización del régimen político hondureño, la importancia geoestratégica del país priorizaría el tema de seguridad y militar. De esta manera, cuando en 1978 la Junta Militar anunció sus intenciones de convocar a elecciones y a una constituyente para la redacción de una nueva constitución política, era evidente que lo hacía desde una posición de fuerza: si bien las fuerzas armadas se enfrentaban a una severa crisis de legitimidad política y el país estaba sumido en una grave crisis económica, no habían sido forzadas a dejar el poder político formal, ni habían tenido que negociar con fuerzas insurgentes, antes bien, seguían siendo un actor clave dentro de la estrategia geopolítica de los EE. UU. en la región (Sosa).

La Asamblea Constituyente de 1981 y la resultante nueva constitución política y la convocatoria a elecciones en noviembre de ese año fueron a todas las luces el resultado de una negociación entre las Fuerzas Armadas y las élites políticas tradicionales, aglutinadas en el sistema de partidos políticos bipartidista más añejo de Centroamérica, bajo la tutela del gobierno estadounidense (Irías y Sosa). De esta manera, las fuerzas armadas se comprometían a "regresar a los cuarteles", a cambio de mantener (y aumentar) el apoyo económico que recibían de los EE. UU. ${ }^{4}$ También, en el marco de la nueva constitución, retenían altos niveles de autonomía con respecto a control civil. En términos políticos, la nueva constitución venía a formalizar y reforzar el sistema bipartidista y la alternancia en el poder entre los partidos Nacional y Liberal. De esta manera, se avanzaba en la construcción de un sistema de elecciones con normas aceptables de transparencia y con mecanismos de democracia representativa, pero sin hacer cambios sustantivos en lo que respecta a la oferta electoral, ni en términos de los derechos y las libertades ciudadanas. De hecho, en la década de 1980, como parte de la estrategia de lucha contra el comunismo, la sociedad hondureña se mantendría bajo un férreo control militar, con formas de represión estatales y paraestatales, como en el caso del infame Batallón 3-16, bajo el liderazgo del general Gustavo Álvarez Martínez, teniendo las desapariciones, ejecuciones sumarias y torturas como parte de 
su repertorio (Barahona, 2005). Esta contradictoria articulación entre represión y violencia de Estado, con un sistema político formalmente democrático y representativo, se vendría a traducir durante toda esta década en una disputa entre organizaciones de la sociedad civil como el Comité de Familiares de Detenidos y Desaparecidos de Honduras (Cofadeh), o el Comité para la Defensa de los Derechos Humanos en Honduras (Codeh), el gobierno civil y las fuerzas armadas.

Si la década de 1980 había sido de una democracia electoral tutelada por militares, la década de 1990 marcaría el paso a un proceso de apertura política, bajo un verdadero control civil. Como mencionábamos anteriormente, con el fin de la Guerra Fría y la lucha contra el comunismo, la viabilidad política y económica de gobiernos autoritarios desciende significativamente, lo cual se articula con un apoyo mucho más decidido desde la política internacional estadounidense por promover procesos de transición hacia la democracia. En este contexto, y con la creciente presión por parte de la ciudadanía, se inicia la desmilitarización de la sociedad hondureña. Por ejemplo, en 1993 se sustrae la investigación policial del ámbito militar y se subordina al ministerio público.

Al año siguiente, se inicia el proceso de regresar a control civil un conjunto de instituciones clave, que habían sido acaparadas por las estructuras castrenses, bajo la justificación de la seguridad nacional; algunas de estas eran la Empresa Hondureña de Telecomunicaciones (HONDUTEL), la Marina Mercante, la Dirección General de Política Migratoria, el Instituto Geográfico Nacional (IGN) y Aeronáutica Civil. También, entre 1994 y 95, y como resultado de la presión desde organizaciones de la sociedad civil, se enmienda la constitución política para eliminar el servicio militar obligatorio. Finalmente, en 1998 se aprueba la Ley Orgánica de la Policía, separándola completamente del control militar y ese mismo año se elimina la figura del Jefe de las Fuerzas Armadas.

La década de los noventa y, particularmente, la llegada al poder de Rafael Leonardo Callejas en 1990 marcan un período de inflexión económica en Honduras mediante un proceso de ajuste estructural. Sin embargo, pensar que es hasta este momento que se inician los esfuerzos por liberalizar a la economía hondureña, sería un error. Ya en enero de 1982 un grupo de personas interesadas en transformar la economía en Honduras le habían entregado al primer presidente del período de transición a la democracia, Roberto Suazo Córdova, un documento en el que se planteaba que la mejor forma de salir de la crisis económica en la que se encontraba el país, era abriéndolo a la inversión extranjera (Leiva de Argueta y Castro). Dicho documento se ha llegado a conocer como el "Memorándum Facussé", debido al rol central de Miguel Facussé en su preparación. No obstante, el rol de Facussé y del grupo de personas que se aglutinaban alrededor de él, y que a partir de 1983 se formalizó en la Asociación para el Progreso de Honduras (Aproh), ${ }^{5}$ no se acaba ahí. Este empresario, de descendencia palestina y dedicado a la agroindustria, se convirtió en uno de los asesores presidenciales más 
importantes de Suazo y fue uno de los ingenieros de la política económica de dicho gobierno, la cual se dirigió a sentar las bases para el posterior proceso de ajuste estructural (Equipo Nizkor).

Sin embargo, como plantea William Robinson (2003), debido a la crisis político-militar que todavía enfrentaba la región en la década de 1980, las posibilidades de atraer inversión extranjera y promover los procesos de liberalización mercantil que buscaban este tipo de grupos no era viable. Habría que esperar a la década de los 1990, con el proceso de pacificación en la región, para que se generaran las condiciones de posibilidad para avanzar con su proyecto económico. Ahora bien, para poder dar cuenta de este proceso, y contextualizar el avance del proyecto neoliberal en el marco y en relación con la transición a la democracia, es importante hablar de personajes tales como Facussé, no en tanto individuo, sino como parte de la élite económica que viene a vehiculizar dicho proyecto. De acuerdo con una parte de la historiografía política de Honduras, a diferencia de lo sucedido en el resto de los países en el istmo, en este país no se desarrolló una burguesía nacional fuerte (Perez-Brignoli; Torres-Rivas), debido al tardío desarrollo de la economía cafetalera (Williams), así como la masiva influencia que el enclave bananero tenía sobre la vida política y económica de la sociedad. Como resultado, el proceso de formación de las clases dominantes estuvo vinculado por muchos años a un conjunto de redes económicas y políticas, vehiculizadas en muchos casos por relaciones de parentesco, tejidas alrededor del enclave y el Estado, entendido fundamentalmente como un botín.

Sería hasta las décadas de 1950 y 1960, particularmente después de la aprobación de la Ley de Desarrollo Industrial en 1958, que se empezaría a desarrollar una incipiente burguesía industrial, alrededor de la ciudad de San Pedro Sula, que llegó a ser conocida como la "capital industrial de Honduras" (Euraque, 1996). Dentro de esta ascendiente burguesía encontramos una significativa presencia de migrantes palestinos, en su mayoría cristianos ortodoxos, que habían llegado al país durante la década de los 1920 y 1930, debido al conflicto armado en el Medio Oriente (Euraque, 2009). Dichos migrantes llegaron al país con cierto capital social y económico que les permitió insertarse en la economía local como comerciantes. Debido a la idea que tenían la mayoría de los migrantes de que se trataba de una estadía provisional, antes de volver a Palestina, y al racismo que marcaba a las élites políticas hondureñas y sus políticas migratorias, esta comunidad de migrantes tenía una vinculación limitada con la sociedad hondureña en general (Lirio). Esta situación empezaría a cambiar en la década de 1950, en parte debido a la declaración del Estado de Israel en 1948, lo cual venía a plantear que su éxodo del Medio Oriente sería permanente, pero también con su paulatino ascenso y consolidación dentro de la élite económica de San Pedro Sula, lo que eventualmente se convirtió en lazos matrimoniales con familias de la élite económica y política hondureña. 
Ya para la década de 1980, los grupos económicos vinculados a varias familias palestinas se encontraban entre los más ricos del país, teniendo una fuerte presencia no solo dentro de la industria manufacturera, sino también dentro del sector financiero, la agroindustria y los medios de comunicación, por mencionar algunos (Euraque, 2009; Lirio). Sin embargo, este creciente poderío económico no se traducía, al menos formalmente en poder político. ${ }^{6}$ ¿Por qué? De acuerdo con Euraque (2009), encontramos una posible respuesta en el argumento de Rodolfo Pastor de que ya para mediados de esa década existía una "falta de correspondencia entre sistema político y estructura social" (28). Así, grupos de importancia dentro de la estructura económica, no se traducían directamente en puestos de importancia dentro del sistema político. Para Euraque, la razón parcial para este fenómeno era el antes mencionado racismo de las élites tradicionales hondureñas, así como la desconfianza de la población en general hacia los "turcos", como se les conoce coloquialmente a las personas de descendencia árabe y palestina.

Como hemos venido mencionando, para la década de 1980 los grupos empresariales familiares de descendencia palestina se habían convertido, con apoyo estatal y en el marco de la estrategia de reformismo militar y apuesta por la integración al mercado común centroamericano, en uno de los grupos de poder económico más importantes en el país. Vinculados a sectores como el comercial, manufacturero y financiero, contaban con claros vínculos con capital transnacional. De esta manera, eran de los sectores más interesados en promover una liberalización de la economía hondureña. Sin embargo, como menciona Robinson (2003), en la década de 1980, las élites económicas hondureñas se encontraban altamente fragmentadas entre "viejos" grupos de poder económico, vinculados a la ganadería y las industrias extractivas (minería y maderas, por ejemplo) y "nuevos" grupos, vinculados más bien a la manufactura liviana (maquila) y finanzas. Según el autor estadounidense, durante la década de 1980, los grupos “viejos" lograron bloquear, o cuando menos atrasar, muchas de las reformas neoliberales que se intentaron impulsar durante esta década, y será hasta la llegada de Callejas en 1990 que estas propuestas se volverán hegemónicas.

Ahora bien, Robinson también menciona que, a diferencia de países como El Salvador, donde los "nuevos" grupos de poder económico vinculados a las reformas neoliberales, organizaron nuevos partidos políticos para vehiculizar las reformas de ajuste estructural, en Honduras tuvieron que hacerlo a través de una penetración de los dos partidos tradicionales (Partidos Liberal y Nacional). Esto lo lograron vinculándose directamente, como miembros de ambos partidos y presentando candidatos a diputaciones, pero sobre todo de manera informal, a través de la entrega de jugosas donaciones políticas a ambos partidos y la influencia sobre los gobiernos de turno, como en el caso antes mencionado de Facussé. De esta manera, el avance del proyecto 
neoliberal en Honduras fue operacionalizado mediante una articulación entre las "viejas" formas de organización política, y las disputas entre "viejos" y "nuevos" grupos de poder económico. Al interior de los partidos políticos, el forcejeo entre estos diferentes proyectos económicos y políticos tomaba la forma de disputas entre caudillos representantes de las diferentes tendencias.

En términos prácticos, las políticas aplicadas en el proceso de instauración del proyecto neoliberal en Honduras, siguen el patrón general que ha sido utilizado en el resto de América Latina: liberalización y desregulación de los mercados, un recorte en los programas de política social universalista, y el paso a estrategias focalizadas, así como la privatización de no solo varias empresas nacionales, sino también de muchos de los espacios de gobernanza y control (Cáceres y Zelaya; Duménil y Lévy; Hibou). En términos específicos, tenemos que hablar de tres programas de ajuste estructural, firmados y apoyados por el FMI: el primero en marzo de 1990, en el gobierno de Rafael Callejas, con la emisión del Decreto 18-90 o Ley de Ordenamiento Estructural de la economía, pero conocido popularmente como el "paquetazo"; un segundo, durante el gobierno del sucesor de Callejas, Roberto Reina (1994-1998), el cual se conoce como el Gran Proyecto de Transformación Nacional, redactado por las personas cercanas a Facussé; y finalmente, un tercer programa durante el gobierno de Carlos Flores Facussé (1998-2002) (Robinson, 2003; Sosa). Algunas de las políticas concretas impulsadas fueron: la devaluación de la moneda nacional, desgravación arancelaria, aumento del impuesto sobre la venta, incentivos fiscales para la atracción de la inversión extranjera directa y la promoción de exportaciones no tradicionales, creación de zonas francas y liberación de las tasas de interés bancarias. Además, se aprobaron un conjunto de leyes específicas y coherentes con el espíritu general del ajuste estructural, como la Ley para la Modernización y Desarrollo del Sector Agrícola (1992), conocida comúnmente como la Ley de modernización agraria y que venía a transformar drásticamente el marco legal de la reforma agraria que se había promovido en el país desde 1972.

En este caso, como en muchos otros, el efecto fundamental del ajuste estructural fue el de saqueo y concentración de activos y recursos que anteriormente se encontraban en manos del Estado u otro tipo de organizaciones no capitalistas, como las cooperativas y empresas asociativas de la reforma agraria, para ahora pasar a manos de un grupo limitado de empresarios y empresas de capital transnacional. ${ }^{7}$ No obstante, esta no fue simplemente una transferencia de activos y recursos, sino el cambio de la lógica de la economía, orientada cada vez menos hacia el mercado doméstico, y cada vez más hacia las exportaciones. ${ }^{8}$

En términos generales, para finales de 1990 los ejes centrales de acumulación de capital en Honduras habían pasado a concentrarse en la manufactura liviana (maquila, sobre todo textil) y los servicios; el sector financiero era una de las actividades centrales. En este proceso, los nuevos grupos de poder económico habían transformado su espacio de acumulación primordial de la economía doméstica, a la región 
centroamericana y la articulación con los flujos de capital transnacional (Robinson, 2003; Segovia). En buena medida, esta transformación se había logrado a través del conjunto de políticas impulsadas por los gobiernos de este período, donde las diferencias entre el Partido Liberal y Nacional eran de forma, pero no necesariamente de fondo. Esto había sido en parte el resultado del proceso de ascenso de los "nuevos" grupos de poder económico que mencionamos arriba, los cuales empiezan a enriquecerse a partir de la década de los 1960, al amparo de las políticas desarrollistas de los gobiernos militares. Sin embargo, sería un error pensar que la instauración del proyecto neoliberal se llevó a cabo sin resistencia por parte de los grupos subalternos, tema al que nos dedicaremos en la próxima sección.

\section{Las luchas subalternas contra el neoliberalismo}

Las décadas de los 1980 y 1990 marca también un período de transición para la protesta social y política en Honduras. Después de la gran huelga bananera de 1954 se inicia en el país un ciclo ascendente de organización política por parte de los grupos subalternos, que sigue en general los contornos de los procesos de formación de clase y de Estado, desencadenados por la profundización de las relaciones de producción capitalista ya mencionados. Así, alrededor del enclave bananero se desarrolla un importante sector sindical, no solo de trabajadores en las plantaciones, sino también de las industrias livianas vinculadas. También, con la formación y fortalecimiento del sector público, se genera un fuerte movimiento magisterial y estudiantil. Finalmente, debido a la concentración de la tierra en manos de un número limitado de grandes terratenientes y empresas transnacionales, se fue consolidando quizás el movimiento campesino más significativo de Centroamérica (Kay; Posas; Thiesenhusen).

Sin embargo, para la década de 1980 este tipo de organizaciones gremiales empiezan a debilitarse, en parte debido a conflictos y fraccionamientos internos, en parte por la crisis económica que vivía el país y en parte debido a la acción directa y activa del gobierno hondureño a través de la cooptación o asesinato de líderes. En este sentido, si bien la represión había sido una constante en la relación entre el gobierno militar y los grupos subalternos, los niveles de violencia directa eran bajos, en relación con lo vivido en los países vecinos. Esta situación vendría a cambiar en las décadas de 1970 y 1980, particularmente después de la victoria sandinista en 1979 y la designación de John Negroponte como embajador en Honduras en 1981 (Kinzer). En este contexto, y bajo la retórica de la Doctrina de Seguridad Nacional, donde desacuerdo político era equiparado con comunismo (Gill), el trabajo de las organizaciones campesinas y magisteriales se vio severamente coartado y sus capacidades políticas debilitadas.

Además, hacia finales de la década de 1970 y principios de los años ochenta, se produce un fraccionamiento al interior del Partido Comunista Hondureño con respecto a cuál debería de ser la respuesta de las masas populares frente a la violencia 
gubernamental. Para ciertos sectores, influenciados por la victoria sandinista y las experiencias guerrilleras en el resto de la región, la respuesta debía de ser armada. Es así como se conforman durante esta década varias organizaciones de corte revolucionario militar, entre las que destacan el Movimiento Popular de Liberación Cinchonero y la Unión Revolucionaria del Pueblo (Canizales). Dichas organizaciones llevaron a cabo varias osadas operaciones, muchas de ellas en apoyo de la lucha guerrillera en El Salvador, pero en términos generales sucumben ante la persecución del ejército que desarticula varios intentos de constituir columnas guerrilleras en el país, y asesina y desaparece a varios de los dirigentes. Así, para 1990, en el contexto de la derrota electoral del FSLN en Nicaragua y el fin de la Guerra Fría, la experiencia guerrillera como tal había desparecido en Honduras.

Dentro de la literatura sobre movimientos sociales en Honduras y Centroamérica en términos más generales (Almeida; Sosa), se plantea que la década de los 1990 marca el ascenso de un nuevo ciclo de conflictividad social en respuesta a las políticas neoliberales. Sin embargo, a diferencia del ciclo de protesta anterior, las identidades políticas y motivos de movilización no tenían tanto que ver con la clase y las relaciones de producción (movimientos sindicales y campesinos), sino más bien con "nuevas" consignas e intereses articulados alrededor de elementos raciales, étnicos, de género y en defensa de la naturaleza. Sin embargo, cuando se pasa del análisis de la movilización social en general a la historia de algunos de estos "nuevos" movimientos sociales, aparecen continuidades que son importantes.

En muchos de los casos, figuras de liderazgo importante en la configuración y empuje de las nuevas organizaciones habían militado, o cuando menos habían tenido cercanía, a las organizaciones guerrilleras recién mencionadas, o a sindicatos y organizaciones campesinas. Este cambio se debía en primer lugar al despliegue de la antes mencionada brutalidad estatal durante la década de 1980, que hacía de la militancia y el activismo público en organizaciones tildadas de "izquierdistas" o "comunistas", prácticamente una sentencia de muerte. También, porque esa misma violencia estatal y paraestatal había dejado fuertes impactos en los tejidos comunitarios donde se había materializado.

Como resultado, la retórica y la forma de organización tradicional de los sindicatos y las centrales campesinas tenía poca capacidad de arrastre. Al mismo tiempo, el hecho de que la represión era paralelamente generalizada en todo el país, pero particularmente focalizada en contra de los liderazgos con alguna presencia nacional, las grandes organizaciones de masas nacionales se volvían más inviables que organizaciones locales alrededor de agendas específicas. Finalmente, el proceso de transición democrática vino acompañado desde la década de 1980 con una apertura a nivel internacional, que eventualmente llegaría a tener incidencia a nivel nacional, sobre temas de reivindicación racial y étnica, así como en temas de género y medioambiente. 
En este sentido, más que un debilitamiento de los movimientos sociales, lo que nos encontramos en este período es una multiplicación algo silenciosa, o silenciada, a nivel nacional, sin espacios de articulación centralizada, pero con claros vínculos a partir de experiencias y afinidades compartidas. Hacia finales de la década de 1990, esta nueva fisionomía de las organizaciones subalternas hondureñas ingresará en un período de creciente antagonismo con el Estado, debido a la cada vez más evidente ruptura de las supuestas promesas de bienestar y democratización de la sociedad, del proyecto neoliberal y de la transición a la democracia.

\section{Huracán Mitch: El capitalismo del desastre en Honduras}

Entre el 26 y el 27 de octubre de 1998, el huracán, y luego tormenta tropical, Mitch se estrelló contra la costa Caribe de Centroamérica. El cuarto huracán más fuerte en la historia de la cuenca del Atlántico vendría a afectar a Honduras particularmente fuerte, con más de cinco mil muertes registradas, alrededor de ocho mil desaparecidos y cerca de 285 mil personas quedaron sin casa. Al final, alrededor de un 38 por ciento de la población hondureña se vio afectada directamente por el huracán y las pérdidas totales causadas por el evento natural superaron el 70 por ciento del producto nacional bruto (FAO 2010). Así, para finales de 1998 la supervivencia de buena parte de la población dependía de la ayuda internacional que empezó a llegar al país de forma masiva.

Lo sucedido posteriormente al desastre es un ejemplo paradigmático de lo que Naomi Klein denomina como el "capitalismo del desastre". De acuerdo con la autora canadiense, se trata de una estrategia política planificada que busca aprovechar la ventana de oportunidad que se abre cuando una sociedad entra en shock y se encuentra tambaleante y en módulo de supervivencia. De esta manera, en el proceso de reconstrucción, se generan condiciones para la acumulación de capital a través del despojo. Para el caso específico del huracán Mitch en Honduras, Klein menciona que:

Dos meses después de que golpeara el [huracán] Mitch, con el país aún cubierto hasta las rodillas de escombros, cadáveres y lodo, el congreso hondureño aprobó un conjunto de leyes que permitían la privatización de aeropuertos, puertos marinos y autopistas y llevó por vía rápida diversos planes para privatizar la compañía estatal de teléfonos, la compañía nacional eléctrica y parte del sector del agua. Asimismo anuló leyes progresistas de reforma de la tierra, haciendo más fácil a los extranjeros comprar y vender propiedades y presionó firmemente a favor de una radical ley minera (esbozada por la industria) que rebajó los estándares medioambientales e hizo más fácil desahuciar de sus hogares a la gente que se encontraba en el paso de las nuevas minas (395).

En general, el tema de las privatización de empresas públicas ha recibido bastante atención, en parte debido a lo generalizado del proceso en toda América Latina y la existencia de movimientos a escala nacional en su contra (Almeida; Harvey; Sosa). 
Lo mismo no sucede necesariamente con los casos del régimen legal de tierras y la minería, por lo cual quisiéramos presentar brevemente un ejemplo de cada caso, para ilustrar la nueva etapa en la instauración del proyecto neoliberal en Honduras y las formas de respuesta de los sectores subalternos.

En el caso de los cambios en el régimen de tierras, nos gustaría concentrarnos en el caso de los garífunas, un grupo indígena y afrodescendiente, cuyas raíces étnicas y culturales se encuentran en la mezcla entre cimarrones (esclavos africanos escapados) y grupos indígenas de la región (caribes y arawakan), que emergieron como un grupo cultural y racialmente diferenciado hacia mediados del Siglo XVII en la isla de San Vicente, de donde fueron expulsados por los ingleses hacia Honduras a finales del Siglo XVIII (Gonzalez). Desde su llegada, los garífunas establecieron sus comunidades a lo largo de la costa Caribe, bajo una lógica de control colectivo de la tierra y organizados alrededor de sus estructuras de parentesco. El hecho de que, para dicho momento, la costa Caribe se encontraba poco integrada al resto del país, les otorgó una autonomía basada en el aislamiento que permitió no solo la supervivencia de sus formas culturales, sino también su desarrollo. Sin embargo, con el pasar del tiempo, y con la integración territorial de la costa Caribe al resto del país, sus tierras se convirtieron en el blanco de diferentes actores, incluyendo al Estado, que las veían como tierras "ociosas" o "vacías", debido a la economía de agricultura de subsistencia y pesca practicada por los Garífunas, prestas a ser "desarrolladas".

Como resultado, desde al menos la década de 1980, se crearon un conjunto de organizaciones políticas garífunas dirigidas a defender su derecho a la tierra y su cultura. ${ }^{9}$ El núcleo de sus reivindicaciones era convertir los títulos de ocupación (reconocen únicamente la presencia de las comunidades en la tierra) que habían conseguido en la década de 1970, como parte de un esfuerzo para evitar la usurpación de sus tierras por terceros, en títulos de propiedad colectivos con dominio pleno. Es así como durante la década de los 1990 se inicia un proceso de titulación comunitaria, que eventualmente llevará al otorgamiento de más de cincuenta títulos a comunidades garífunas por parte del Estado (Brondo, 2018).

En principio, esto puede ser leído como una gran victoria para las comunidades garífunas. Sin embargo, el balance general ha sido contradictorio. Primero que todo, la mayoría de los títulos plenos se limitan a las tierras ubicadas en los cascos centrales de las comunidades, dejando por fuera tierras que son reivindicadas como ancestrales por los garífunas. Además, según Keri Brondo (2018): “los títulos comunitarios eran un mecanismo para promover la inversión privada, al aumentar la seguridad sobre la tierra. Es decir, los títulos comunitarios estimulaban la inversión en territorio Garífuna" (187).

De acuerdo con el antropólogo estadounidense Cristopher Loperena (2017a), el proceso de reconstrucción de Honduras tras Mitch generó las condiciones ideales para la expansión y aceleración del proyecto neoliberal. De acuerdo con el gobierno de 
Honduras, una de las razones detrás del nivel de devastación dejado por el huracán había sido el uso poco sostenible de los recursos naturales, por lo cual el proceso de reconstrucción también tenía que pasar por promover un modelo de desarrollo más sostenible, central para esta idea era la promoción del turismo, como una "industria sin chimeneas" que podría reactivar la economía nacional. En esta línea, se promovieron varias políticas para incentivar a este sector, incluyendo la exoneración de impuestos, pero para nuestra historia, quizás la más importante fue la reforma por parte del Congreso Nacional, del artículo 107 de la Constitución Política, solo dos días después de la catástrofe.

Originalmente, dicho artículo prohibía la venta de tierras costeras a personas extranjeras; tras la reforma, se hacía una excepción para aquellos casos donde la finalidad de la adquisición fuera el desarrollo de la industria turística. En el caso de las tierras garífunas, esta reforma, así como las antes mencionadas con respecto a la titulación, abrieron un proceso ascendente de despojo de tierras y conflicto político entre las organizaciones comunitarias, las desarrolladoras turísticas y el Estado, quien por lo general ha tomado el bando de las segundas (Anderson, 2012; Brondo, 2013; Loperena, 2017b; Wrathall).

Como resultado general de estas políticas, el turismo se convirtió, junto con la maquila y los agronegocios, en uno de los motores de la atracción de inversión extranjera directa. No obstante, como también menciona Loperena (2017a), esto no implicó la desaparición de otras actividades extractivas como la minería, sino más bien su combinación.

El caso del desarrollo de la minería en el período posMitch amerita un tratamiento más detallado que el que le podemos dar en este espacio, por lo que nos limitaremos a una caracterización muy general, que nos permita dar algunas luces sobre la forma de implementación del proyecto neoliberal y la reacción de las organizaciones subalternas. De manera similar a lo sucedido en el caso de la reforma del Artículo 107 de la Constitución Política, a finales de 1998, pocos meses después del huracán Mitch, el Congreso Nacional hondureño aprobó la Ley General de Minería (Decreto N. 29298), el cual venía a sustituir el Código de Minas de 1968 y que generaba un conjunto de exoneraciones fiscales e incentivos para atraer capital transnacional y desarrollar la industria. Como resultado, "tras la aprobación de esta ley se entregaron $35 \mathrm{mil} \mathrm{km²} \mathrm{del}$ territorio nacional a través de 155 concesiones mineras" (ERIC).

Al mismo tiempo, desde su aprobación, esta Ley fue cuestionada y denunciada por distintas organizaciones de la sociedad civil. Entre los cuestionamientos más importantes encontramos: el permiso para la expropiación forzosa de sujetos privados o comunidades que se nieguen a vender sus tierras para el desarrollo de la minería; el establecimiento de contribuciones mínimas para las municipalidades y el fisco hondureño; la ausencia de una reglamentación clara para el cierre de las minas, eliminando cualquier procedimiento de oposición o sanción a las empresas; el nivel 
de exoneraciones otorgadas a las empresas; la posibilidad de desarrollar procesos de exploración y explotación en zonas protegidas; disminución de las regulaciones ambientales y la priorización del derecho al agua y la propiedad de las empresas, en detrimento de las comunidades (ERIC; ICEFI).

El resultado de esta expansión de la minería fue un conjunto de conflictos en aquellos lugares donde se ubicaban los proyectos. En general, la instalación de las minas presenta dos momentos: inicialmente las empresas buscan convencer y sobornar a las comunidades. Cuando este primer intento no funciona y las comunidades se siguen oponiendo activamente a la instalación de la mina, el siguiente paso es el amedrentamiento, represión e inclusive asesinato de líderes y activistas comunitarios por parte de las guardias contratadas por las empresas o por elementos militares y paramilitares vinculados a las fuerzas armadas hondureñas (ERIC; ICEFI; Middeldorp y Le Billon).

Otro elemento que es importante agregar a las dinámicas de conflicto comunitario es que, como menciona el antropólogo holandés Nick Middeldorp, en su estudio etnográfico sobre la oposición a la minería en Honduras, inicialmente, la oposición y la movilización social no se daba en contra de la minería como tal, sino en contra de la usurpación de tierras y el cercamiento a recursos como el bosque y las fuentes de agua, como parte de la instalación de las empresas. Es con el tiempo, y en parte gracias al trabajo realizado por organizaciones ambientalistas hondureñas y extranjeras, que se va generando un proceso de concientización de los efectos ambientales y sobre la salud que tiene la minería. De este proceso de articulación entre experiencias compartidas y organizaciones operando en diferentes escalas, fue surgiendo durante los 2000 un vibrante movimiento social antiminero, al menos bajo el formato que se venía dando en el marco de la Ley General de Minería de 1998.

Con esto en mente, se utilizó una estrategia que combinaba la movilización popular, con la presentación de un recurso de inconstitucionalidad de trece de los artículos de dicha Ley ante la Corte Suprema de Justicia. Para mediados de la década, dicha estrategia empezó a cosechar sus frutos. Primero que todo, la creciente oposición popular obligó al gobierno del entonces presidente Ricardo Maduro (2002-2006) a suspender en agosto del 2004 el otorgamiento de nuevas concesiones mineras, hasta que no se creara también una política ambiental minera. Dicha moratoria fue posteriormente ratificada en el 2006 por el gobierno entrante de Manuel Zelaya, pero en este caso condicionada a la creación de una nueva ley de minería (ERIC 2016). En noviembre de ese mismo año, la Corte Suprema de Justicia falló a favor del recurso presentado por el movimiento antiminero, declarando como inconstitucionales los trece artículos denunciados (ICEFI).

Así, para principios de la década de los 2000, distintas manifestaciones regionales y temáticas, como la Ofraneh o el movimiento antiminero, empezaron a vincularse a nivel nacional, en la forma de reuniones de trabajo y movilizaciones populares, 
como la denominada Marcha de la Dignidad, llevada a cabo en agosto del 2003, que puede ser denominada el punto de arranque de estas nuevas formas de articulación política. Una organización que empieza a tomar forma durante este período, y que a la postre tendrá un fuerte rol durante el gobierno de Zelaya, era la Coordinadora Nacional de Resistencia Popular (CNRP), la cual según Kristina Pirker y Omar Núñez aglutinaba diversas entidades sindicales, campesinas, magisteriales, estudiantiles e indígenas, entre otras, que exigía al gobierno un petitorio amplio que incluía la derogación de las leyes de minería que favorecen a las grandes compañías y de la Ley Marco del Agua Potable y Saneamiento, aprobada en 2003, que estipulaba la municipalización del servicio y su privatización. Además, esta organización social planteó la necesidad de que el Estado estableciera un control de precios ante el encarecimiento de los productos básicos que experimentaba el país, así como la suspensión de todos los proyectos de construcción de represas hasta que se definiera una propuesta que se sostuviera sobre la protección del medio ambiente, entre muchas otras demandas (129).

Visto en su conjunto, el huracán Mitch y el posterior período de reconstrucción aceleraron un conjunto de procesos y dinámicas que se habían iniciado algunos años antes. Por un lado, el proyecto neoliberal de las élites transnacionalizadas encontró en el shock dejado por el desastre la oportunidad para promover en articulación con las organizaciones financieras internacionales, un conjunto de leyes y reformas que venía a poner a disposición del mercado activos (sobre todo tierras) que anteriormente se encontraban fuera del alcance de estos (cooperativas y empresas asociativas campesinas, por mencionar un par). Como resultado, se dio un cambio en los ejes centrales de acumulación hacia el sector financiero, de agronegocio de exportación (sobre todo palma africana), el turismo, la manufactura liviana (maquila) y un fuerte impulso hacia otras actividades extractivas como la minería, en detrimento del mercado interno y la pequeña producción nacional.

Por otro lado, nuevas formas de organización social, con arraigos y presencias regionales y vinculadas alrededor de temas no necesariamente gremiales (defensa del agua, de la salud, de los derechos culturales, entre otros) empiezan a aparecer en el espacio dejado entre la represión antisindical y campesina (legado del período de Guerra Fría) y la promoción de nuevos marcos de derechos humanos y ciudadanos, vinculados a la transición democrática formal del país. Dichas formas de organización social empezaron a tener mayor presencia a nivel nacional, articulándose alrededor de una lista amplia de agravios compartidos y que, como el caso de la Ley General de Minería muestra de forma clara, iniciaba a presentarse como un actor a ser tenido en cuenta.

Finalmente, en el medio de estos dos procesos, se erguía un aparato institucional estatal, controlado en buena medida por las élites políticas tradicionales y las fuerzas armadas, las cuales, si bien había perdido parte de su preeminencia durante la década de 1990, seguían siendo un actor determinante dentro de las dinámicas políticas nacionales. Como resultado, el aparato estatal mostraba poca flexibilidad, tanto para 
atender los reclamos provenientes desde "abajo", como para gestionar las fricciones y conflictos entre las "nuevas" y "viejas" élites y sus proyectos económico-políticos. Así, Honduras no solo aparecía como un país con una situación socioeconómica estancada y deplorable, con altos niveles de pobreza, desigualdad y endeudamiento, sino también con una estasis política que impedía impulsar cambios políticos. Es en este contexto que Zelaya gana las reñidas elecciones del 2005 y se inicia el camino hacia el golpe de Estado del 2009; el cual como argumentaremos, si bien no era inevitable, encontraba en estos procesos antes descritos, sus condiciones de posibilidad. Pasamos a este tema en la próxima sección.

\section{El preámbulo del golpe: Las elecciones del 2005 y el "giro a la izquierda" de Zelaya}

Las elecciones nacionales de Honduras en el 2005 estuvieron marcadas por un alto abstencionismo de más del 50 por ciento y una reñida disputa entre Manuel Zelaya, del Partido Liberal, y Porfirio Lobo del Partido Nacional. Al final, Manuel Zelaya fue electo con poco menos de la mitad de los votos válidos emitidos y en medio de una gran polémica sobre un posible fraude y los atrasos en el proceso de contar los votos y hacer la declaración oficial del candidato ganador. En términos generales, los temas centrales de dicha campaña electoral fueron la seguridad y la violencia, por un lado, y la de corrupción y transparencia, por el otro (Ajenjo Fresno; Taylor-Robinson).

En este sentido, las condiciones en que se inicia la administración de Zelaya eran un claro reflejo del proceso de instauración del proyecto neoliberal en Honduras que hemos venido caracterizando en las páginas anteriores. Mucho se ha escrito sobre las acciones que impulsó el presidente Manuel Zelaya y que llevaron a su expulsión por parte de las fuerzas armadas y no es nuestra intención repetirlas. Quisiéramos más bien estudiar brevemente tres elementos que nos ayudan a enlazar los procesos históricos que hemos venido caracterizando, con las posiciones que ciertos actores vendrían a ocupar con respecto a la coyuntura política, generando así las condiciones de posibilidad para el golpe de Estado. Dichos elementos son: 1) la crisis energética del país y los esfuerzos desde el gobierno por superarla; 2) la propuesta de participación ciudadana como eje central de la campaña de Zelaya; y 3) la ruptura del pacto de la transición democrática, al abrirle un espacio a los sectores subalternos para presentar y legitimar sus agravios frente al Estado.

En lo que respecta a la crisis energética, el gobierno entrante, apenas cuatro días después de ser juramentado declaró un "estado de emergencia energética" y decidió asumir el control directo de la Empresa Nacional de Energía Eléctrica (ENEE), debido a la inminente bancarrota en la cual se encontraba la institución (pérdidas de unos USD 160 millones para el 2006) y su incapacidad para abastecer la demanda nacional. En un país cuya producción energética descansa fundamentalmente en la 
quema de combustibles fósiles, los problemas financieros de la ENEE estaban directamente conectados a las fluctuaciones de los precios del petróleo a nivel internacional. Así las cosas, mediante decreto ejecutivo Zelaya aprobó un fondo de emergencia por USD 15.8 millones en subsidios para combustibles, para intentar frenar el alza de los precios, mientras se encontraba una solución más definitiva al problema (Cunha Filho, Coelho y Pérez Flores). El problema fundamental con el sector energético hondureño era el control absoluto que tres empresas transnacionales (Esso, Texaco y Shell) tenían sobre la importación del petróleo y derivados, lo cual se traducía en precios bastante altos, así como en una limitada capacidad por parte del Estado para intervenir. Esto no era un problema nuevo, ya durante el gobierno previo de Ricardo Maduro (2001-2005), se había formado una Comisión de Notables para buscar alguna respuesta estructural al problema energético. Una de las recomendaciones de la Comisión era romper los contratos draconianos que le permitía a estas empresas controlar la importación de hidrocarburos al país a su antojo, y realizar una licitación internacional para contratar a alguna empresa que garantizara mejores precios.

En el momento que el gobierno de Zelaya empezó a avanzar en esta dirección, se encontró con una férrea resistencia, no solo por parte de las empresas transnacionales antes mencionadas, y que además boicotearon el concurso, sino también del embajador estadounidense, Chad Ford, quien declaró que esta medida significaba cambiarle las reglas del juego a la inversión extranjera de "la noche a la mañana”, sentando un mal precedente; opinión que era compartida por buena parte una parte del sector empresarial nacional que consideraban que las empresas estarían en todo su derecho de demandar al país por sus pérdidas en los tribunales consignados para estos casos en el marco del Cafta (Pirker y Núñez). Al final, la licitación fue adjudicada a la empresa estadounidense ConocoPhillips en enero del 2007. Seguidamente, Zelaya ordenó la confiscación de todos los puertos y tanques de almacenamiento de hidrocarburos en manos de las tres empresas y su transferencia a ConocoPhillips. Sin embargo, esta iniciativa no duró mucho, ya que el gobierno se vio obligado a echar marcha atrás con el proceso confiscatorio debido a una protesta oficial de la Embajada estadounidense (Cunha Filho et al.).

Es a partir de este momento que se inicia el supuesto giro a la izquierda del gobierno de Manuel Zelaya. En julio de ese mismo 2007, el mandatario hondureño visitaría Nicaragua para la celebración de los 28 años de la Revolución sandinista, atrayendo la crítica tanto de la derecha hondureña, como de la Embajada de los EE. UU. Para diciembre de ese mismo año, Zelaya informa que Honduras estará uniéndose a la iniciativa del gobierno venezolano de Petrocaribe para asegurar la importación de hidrocarburos a un costo más bajo. El 22 de julio del 2008, un mes después de que llegaran los primeros envíos petroleros venezolanos, el mandatario hondureño informó sobre su intención de que el país se uniera al proyecto de integración regional de la ALBA, liderado por el presidente venezolano Hugo Chávez. La forma que fueron 
tomando estos sucesos nos dejan algunos puntos importantes a tomar en cuenta. Por un lado, que la rigidez del sistema político hondureño, particularmente de sus élites económicas y de la presión impuesta desde la embajada estadounidense para defender los intereses de sus empresas, hacía fundamentalmente imposible la generación de cambios dentro del marco político e institucional existente. Por otro lado, que la política regional venezolana, acompañada de sus galones de petróleo, generaba una ventana de oportunidad, un conjunto de condiciones materiales, para que los gobiernos de la zona promovieran políticas que no estuvieran exactamente alineadas con los intereses estadounidenses y los de las empresas trasnacionales.

Con respecto al segundo punto, la propuesta participativa de Zelaya, desde el proceso de elección interna del Partido Liberal, el futuro presidente montó su proyecto político alrededor de la idea de la participación ciudadana y la lucha en contra de la corrupción. Así, recién iniciado su mandato el Congreso Nacional aprobó una nueva Ley de Participación Ciudadana que abría ciertos espacios para la participación formal de la sociedad civil en decisiones gubernamentales. Ley en la cual posteriormente se ampararía la encuesta popular que a la postre desencadenaría su expulsión de la silla presidencial. La decisión de articular su gobierno alrededor de la participación ciudadana era un claro reflejo de la coyuntura política.

Por un lado, la creación de espacios de participación era uno de los requisitos impuestos por los OFI, como parte del ingreso del país en el 2005 a la Iniciativa de Países Pobres Altamente Endeudados (HIPC, por sus siglas en inglés) (Cunha Filho et al. 2013). Por el otro, no solo Zelaya había estado involucrado en varios procesos de política social en gobiernos anteriores que lo habían puesto en contacto directo con actores de la sociedad civil, sino que también varios de sus asesores políticos habían sido parte de movimientos de izquierda durante la década de 1970, por lo cual la idea de abrir espacios de participación popular era no solo parte de su retórica, sino también de la sensibilidad política de su círculo cercano (Pirker y Núñez). ${ }^{10}$ Además, se le puede agregar el contexto de baja legitimidad política del sistema político, donde plantear una postura participativa podría venir a oxigenar la posición del gobierno, particularmente después de su llegada a la silla presidencial desde una posición de debilidad relativa. En cualquier caso, ya fuera por afinidad personal, por obligación externa o como parte de una estrategia política, esta propuesta de abrir espacios de participación desde la ciudadanía generaría un conjunto de procesos que a la postre, son centrales para entender el golpe de Estado.

Como mencionamos anteriormente, desde el principio el gobierno de Manuel Zelaya se encontraba en una posición de relativa debilidad. En el espacio legislativo, el Partido Liberal gozaba de una leve mayoría que no era suficiente para impulsar propuestas de manera solitaria. Pero además, al interior de su partido el mandatario tampoco contaba con un apoyo estable o absoluto. Al exterior, como vimos en el caso de la crisis energética, las decisiones del gobierno no eran del agrado ni de una parte 
del sector empresarial, ni de la embajada estadounidense. Esta situación de aislamiento, lejos de mejorar, iba empeorando al tiempo que Zelaya empujaba hacia el frente un conjunto de políticas que iban en contra de los intereses y las sensibilidades de las elites hondureñas, tales como el ingreso a la ALBA o un aumento del 60 por ciento del salario mínimo. Al final, de la combinación entre este aislamiento, las sensibilidades de izquierda de Zelaya y particularmente de su círculo cercano, las condiciones de posibilidad abiertas por la propuesta geopolítica venezolana y la plataforma gubernamental de participación ciudadana surgiría el llamado "giro a la izquierda" del gobierno (Cunha Filho et al.; Pirker y Núñez).

Ahora bien, en términos generales, existe un consenso en la literatura de que es este giro a la izquierda y la respuesta desde las élites políticas y económicas, incapaces de aceptar cualquier cambio al estatus quo, lo cual terminó con la expulsión de Manuel Zelaya por parte de las fuerzas armadas. Sin embargo, como mencionábamos antes, estos análisis tienden a concentrarse en el espacio de la política formal y los procesos institucionales. Así las cosas, temas como el de la ALBA y la posible reforma constitucional tienden a acaparar toda la atención, invisibilizando no solo la creciente movilización popular, sino lo que la respuesta del gobierno frente a dicha movilización significaba en términos más estructurales del sistema político hondureño. Cuando pasamos de los estudios que buscan explicar directamente el golpe de Estado, a aquellos estudios de caso que buscan analizar más situaciones específicas y de cómo dichas realidades fueron atravesadas por el golpe, lo que encontramos es un consenso distinto (Brondo, 2013; Edelman y León; Graham; Loperena, 2017a; Middeldorp). En general, estos estudios plantean que la mayoría de los movimientos sociales se acercaron al gobierno de Zelaya y su propuesta de participación ciudadana con bastante sospecha. No solo venían en el mandatorio un perfecto ejemplo de un miembro de la oligarquía tradicional hondureña, sino que en varias ocasiones la respuesta gubernamental frente a la protesta social había sido reprimida de la misma manera en que lo habían hecho los gobiernos anteriores (Sosa). Sin embargo, al mismo tiempo, a diferencia de los otros gobiernos anteriores, el gobierno de Zelaya generó espacios de diálogo sobre ciertos temas.

Ya mencionamos el caso del movimiento antiminería, donde el gobierno respondió a los reclamos de las organizaciones sociales reafirmando la moratoria sobre la actividad, pero también mostrando su anuencia a que se creara una nueva ley minera que tomara en cuenta las propuestas de la sociedad civil (Middeldorp). Otro tanto se podría decir sobre el reclamo del campesinado organizado hondureño por empujar un nuevo proceso de reforma agraria en el país. Como en el caso de la minería, la tematización del problema de la tierra en este período inició con un conjunto de movilizaciones. En este caso, las más importantes fueron un conjunto de ocupaciones de tierra en zona del Bajo Aguán, en la costa norte hondureña. Como mencionamos anteriormente, fue en esta región donde la venta de tierras de la reforma agraria tomó más fuerza, 
y es ahí donde, a partir del 2000, diferentes organizaciones campesinas empezaron a "recuperar" tierras que consideraban les habían sido arrebatadas de forma injusta.

Con el pasar de los años el conflicto siguió en escalada y ya para el 2006 la región vivía en un estado de conflicto abierto entre organizaciones campesinas y guardias privadas de los terratenientes. En este contexto, hubo un acercamiento por parte de las organizaciones campesinas al mandatario para intentar detener el conflicto, y como resultado de esta negociación el 31 de marzo del 2008, el presidente firmó el Decreto Ejecutivo 18-2008. El objetivo fundamental del decreto era resolver la gran cantidad de casos que tenía pendientes el Instituto Nacional Agrario (INA) en todo el país, así como distribuir una parte de las tierras fiscales, a nombre del Estado, que eran ocupadas ilegalmente por terceros (Ríos). El efecto del 18-2008 fue doble: por un lado, acercó al sector campesino al gobierno, a partir de abrir un diálogo sobre un tema que había sido ignorado por los gobiernos anteriores; por el otro, recibió una fuerte y frontal crítica por parte de los terratenientes y ganaderos, los cuales a través de la Federación Nacional de Agricultores y Ganaderos (FENAGH) cuestionaron la constitucionalidad de dicho decreto frente a la Corte Suprema de Justicia. El resultado, fue un aumento en los niveles de violencia en contra de las organizaciones campesinas (Edelman y León).

En general, estas breves ejemplificaciones nos muestran cómo Zelaya, desde su aislamiento relativo con respecto a los actores políticos tradicionales, se acercó a las organizaciones de los sectores subalternos mediante la generación de ciertos canales de diálogo que históricamente no habían existido. De estos procesos se fue creando una alianza coyuntural alrededor de una posible constituyente que incluyera muchos de los temas empujados por las organizaciones civiles (Shipley, 2016), la que a la postre llevaría a la encuesta que detonaría la expulsión de Zelaya Rosales. Este acercamiento venía a romper el pacto que inició la "transición a la democracia". Como mencionamos anteriormente, dicho pacto se limitó a dos actores, las fuerzas armadas y las élites tradicionales políticas, organizadas en los Partidos Liberal y Nacional. Como no tuvieron que negociar con ninguna fuerza subalterna, lo acordado era fundamentalmente cómo dividir el Estado botín y las cuotas de poder y acceso a los puntos de extracción de renta. Uno de los elementos centrales de este pacto era exactamente la exclusión de las organizaciones populares. Así las cosas, el giro a la izquierda de Zelaya, también era una apertura, por pequeña y titubeante que fuera, para que las organizaciones políticas subalternas pasaran a tener un rol más activo en el direccionamiento político del país. Como el 28 de junio del 2009 nos enseñó, el sistema político hondureño y particularmente la forma en que se venía instaurando el proyecto neoliberal en el país, no estaba en capacidades de aceptar un proceso de democratización que no fuera desde “arriba" ni alineado con el proyecto geopolítico estadounidense. En el proceso, también nos enseñó las limitaciones de la "transición a la democracia", tanto en términos analíticos como prácticos. 


\section{Conclusiones}

En este artículo hemos argumentado que en términos generales, los análisis que se han llevado a cabo del golpe de Estado en Honduras del 2009 muestran muchos paralelismos con la literatura sobre la "transición a la democracia" en Centroamérica. Particularmente en lo que respecta al énfasis que se le da a las dinámicas institucionales y de cultura política y la separación que se realiza entre el proceso político (democracia) y el económico (neoliberalismo). Siguiendo la propuesta de William Robinson (1996, 2003), consideramos que dicha separación esconde más de lo que enseña, ya que no solo ambas "transiciones" se llevan a cabo en el mismo período, sino que parecen articularse de manera igualmente armoniosa tanto con el proyecto geopolítico estadounidense, como con los intereses del capital transnacional y un sector de la élite doméstica.

En este sentido, hemos privilegiado el estudio del proceso de instauración del neoliberalismo, entendido como un proyecto de clase, para explorar el lugar en que distintos actores quedaron colocados con respecto al proceso en términos más generales. Así las cosas, entendemos el inicio de la "transición a la democracia" en la década de 1980 como un pacto entre las fuerzas armadas y las élites económicas y políticas hondureñas, en el marco de lo definido como posible por los intereses geopolíticos estadounidenses. Debido en parte a la sensibilidad política conservadora de estos actores dominantes, debido en parte a la ausencia de actores subalternos en la negociación, los contornos de lo que vendría a ser la "transición democrática" estaban definidos por los intereses de los primeros, así como la exclusión de los segundos de cualquier espacio de decisión política. Así las cosas, las siguientes décadas estuvieron marcadas tanto por una cierta democratización en términos de derechos individuales y ciudadanos, al mismo tiempo que se impulsaba un proceso de despojo y liberalización económica. Consideramos que esta combinación, por contradictoria que pueda parecer, es el núcleo central de la experiencia histórica de la "transición a la democracia" en Centroamérica.

Al mismo tiempo, a como el mismo proceso económico y político iba erosionando la legitimidad del sistema político, y sobre todo de los actores dominantes, iba aumentando la conflictividad social bajo una lógica más molecular (diferentes temas) y descentralizada (movimientos locales y regionales). En este sentido, la estela de destrucción que dejó a su paso el huracán Mitch en 1998 venía a sentar de forma clara lo que estaba en juego en el país desde la década de 1980. Por un lado, las élites económicas y políticas nacionales, acompañadas de sus aliados transnacionales, aprovecharon el shock generado por el desastre para avanzar su proceso de liberalización y despojo. Por el otro, del lado de los grupos subalternos, quedaba en evidencia la incapacidad y falta de interés que tenían las élites para promover un proceso político más inclusivo. Como resultado, las organizaciones políticas subalternas entraron en un proceso de 
articulación nacional facilitado por ciertas continuidades entre los "viejos" movimientos sociales de corte clasista, y los "nuevos" movimientos sociales de corte más bien identitario, donde la Coordinadora Nacional de Resistencia Popular es uno de los más claros ejemplos.

Para las elecciones del 2005, lo que encontramos en Honduras era una disputa hegemónica que se mostraba parcialmente en el deterioro de la legitimidad del sistema político electoral formal, pero que resonaba en la creciente articulación y combatividad de las organizaciones políticas subalternas. Así las cosas, cuando Manuel Zelaya Rosales llega a la silla presidencial, muchas de los elementos que eventualmente desencadenarían en su expulsión estaban presentes. Temas como su propuesta de "participación ciudadana" y la crisis energética eran temas que ya venían tomando forma desde al menos el gobierno de Maduro, en el marco de la crisis económica generalizada y el ingreso a la HIDC. Más aún, las primeras decisiones políticas del gobierno entrante, incluyendo la configuración del gabinete o el voto de apoyo a las supuestas bondades del Cafta, calzaban perfectamente con los patrones de la política tradicional hondureña. En este sentido, compartimos la tesis de que el supuesto "giro a la izquierda" de Zelaya estuvo más marcado por su aislamiento político, y un conjunto de circunstancias contextuales particulares (el proyecto geopolítico venezolano, la sensibilidad política del círculo cercano a Zelaya, entre otras) (Cunha Filho et al.; Pirker y Núñez).

No obstante, también consideramos que posiblemente el mayor "pecado" que cometió el gobierno de Zelaya fue la inclusión de los sectores subalternos dentro de las estructuras de decisión política. Esta decisión, por más coyuntural y titubeante que fuera, venía a romper el pacto que había dado inicio al proceso de "transición democrática", o de instauración neoliberal en nuestra propuesta. Al mismo tiempo, mostraba los límites de lo posible, tanto en términos de la inclusión política que podía admitir el sistema político hondureño, como del proyecto geopolítico estadounidense, en su disputa con el proyecto liderado por Hugo Chávez. También muestra los límites de la propuesta de la "transición a la democracia", amarrada normativa y analíticamente a una definición restrictiva de democracia, perfectamente congruente con el proyecto neoliberal, y fundamentalmente incongruente con cualquier intento de proyecto político alternativo.

\section{Notas}

1 En Honduras, las elecciones nacionales incluyen tres urnas electorales, una para la elección presidencial, otra para la de las diputaciones y una tercera para la definición de las alcaldías. La propuesta de Manuel Zelaya era la inclusión de una cuarta urna en la que el electorado se manifestara a favor o en contra de la realización de una asamblea constituyente.

2 Ya que el fin de este artículo no es en sí una discusión a profundidad sobre la literatura referente a la "transición democrática" en América Latina, se ha optado por presentar sus rasgos principales, a través de autores que la han analizado desde una perspectiva crítica. 
Para un acercamiento más "puro" a dicha corriente analítica se recomienda el trabajo de Guillermo O’Donnell y Phillippe Schmitter (2013).

Rodas, a diferencia de Villeda, presentaba un estridente discurso antimilitarista que amenazaba el ascendente poder político y económico que gozaban las fuerzas armadas hondureña a partir de la constitución política de 1957, la cual les daba un amplio margen de autonomía política y económica, con respecto al poder civil. Según la mayoría de analistas, dicha autonomía había sido el resultado de una negociación entre la cúpula del Partido Liberal y las fuerzas armadas, para asegurar la llegada de Villeda Morales a la silla presidencial (Argueta; Barahona, 2005; Holden).

La importancia militar y geoestratégica de Honduras dentro de la política estadounidense era tal que, entre 1980 y 1984, la cooperación militar de EE. UU. dirigida al país centroamericano, pasó de 4 a 77 millones de dólares. Cuando le sumamos el total de ayuda económica, el número supera los USD 200 millones, lo que hacía a Honduras, el octavo mayor recipiente de la ayuda internacional estadounidense en este período (Kinzer 2)

Organización compuesta por empresarios y oficiales de las fuerzas armadas hondureñas, con un claro componente anticomunista.

Son pocas las personas de descendencia palestina que han participado directamente en puestos de elección popular, la gran excepción es Carlos Flores Facussé, quien fue electo presidente en 1998. Existen otras figuras como Jorge Johnny Handal Hawit y Carlos Gabriel Kattan Salem que han sido electas al menos en cuatro ocasiones como diputados desde 1989 (Barahona, 2018).

Por ejemplo, solo dos años después de la implementación de la Ley de modernización agraria, la mitad de las tierras que habían sido distribuidas durante el proceso de reforma agraria, habían sido vendidas por las cooperativas y empresas asociativas, y pasado a manos privadas. En el caso del Bajo Aguán, región en la Costa Norte del país que durante los 1970 y 1980 había sido el centro neurálgico de la reforma agraria hondureña, el número sube a siete de cada diez hectáreas, de las cuales un 34 por ciento quedaron en manos del antes mencionado Miguel Facussé y su Corporación Dinant (Macías).

Eduardo Baumeister, en un estudio sobre las transformaciones regionales con respecto a la seguridad alimentaria, plantea que Honduras pasó de producir un $90.4 \%$ del consumo interno de cereales, a un $80.4 \%$ en 1990 y a un $49 \%$ en el 2009. Al mismo tiempo, entre 1990 y el 2010 aumentó la cantidad de hectáreas dedicadas a la producción de palma africana y caña de azúcar, ambas fundamentalmente para la exportación o como materia prima de productos de exportación, en más de un $169 \%$.

la Organización de Desarrollo Étnico Comunitario (Odeco), creada en 1992. La primera es una organización de base popular y una línea política más confrontativa con respecto al gobierno. Odeco, por su parte busca operar más bien como un intermediario entre las comunidades Garífunas, el Estado y los organismos internacionales. Su respuesta al golpe de Estado del 2009 ilustra bien las diferencias entre ambas. Mientras que Ofraneh se ha mantenido como una de las organizaciones más críticas del golpe y de los gobiernos conformados posteriormente, Odeco ha buscado generar líneas de diálogo con esos mismos gobiernos y ha llegado incluso a tener miembros de la organización en puestos de gobierno.

10 Sobresale dentro de este círculo central del presidente Zelaya la figura de Patricia Rodas Baca, quien es vista por muchos analistas como la arquitecta del acercamiento del gobierno al proyecto Bolivariano. Rodas Baca, es la hija del antes mencionado Modesto Rodas Alvarado (Pirker y Núñez). 


\section{Bibliografía}

Aguilar, Carlos. ¿Cómo y por qué del Golpe de Estado en Honduras? La sinopsis de un proceso de pacificación y democratización fallido en la región. Realidad: Revista de Ciencias Sociales y Humanidades, 121(2009): 699-707.

Ajenjo Fresno, Natalia. Honduras: nuevo gobierno liberal con la misma agenda política. Revista de ciencia política (Santiago) 27 (2007): 165-181.

Alcántara Sáez, Manuel. Centroamérica: viejo escenario en tiempos nuevos de crisis. Política Exterior, 131(2009): 1-10.

Almeida, Paul. Democratization and the Revitalization of Popular Movements in Central America. Movements in Times of Democratic Transition. B. Klandermans y C. van Stralen, eds. Philadelphia: Temple University Press, 2015. 166-185.

Anderson, Mark. Garífuna activism and the corporatist Honduran state since the 2009 coup. Black Social Movements in Latin America. J. Muteba, ed. New York: Palgrave MacMillan, 2012. 53-73.

Anderson, Thomas P. The War of the Dispossessed: Honduras and El Salvador. Lincoln: University of Nebraska Press, 1983.

Argueta, Mario. Ramón Villeda Morales: luces y sombras de una primavera política. Tegucigalpa: Editorial Guaymuras, 2009.

Barahona, Marvin. Honduras en el siglo XX: Una síntesis histórica. Tegucigalpa: Editorial Guaymuras, 2005.

Barahona, Marvin. Élites, redes de poder y régimen político en Honduras. Tegucigalpa: Editorial Guaymuras, 2018.

Barrachina Lisón, Carlos. Democracia, política y violencia en honduras (2006-2014). Península, 11, 1(2016): 25-64.

Benítez, Raúl. La crisis de Honduras y el Sistema interamericano: El triunfo del realismo sobre los principios. Foreign affairs: Latinoamérica, 9, 4(2009): 75-84.

Borón, Atilio. Honduras: la futilidad del golpe. Centre Tricontinental, 29(2009).

Boyer, Jefferson. Agrarian Capitalism and Peasant Praxis in Southern Honduras (Tesis doctoral). University of North Carolina at Chapel Hill, 1982.

Brondo, Keri Vacanti. Land Grab: Green Neoliberalism, Gender, and Garifuna Resistance in Honduras. Phoenix: University of Arizona Press, 2013.

Brondo, Keri Vacanti. 'A Dot on a Map': Cartographies of Erasure in Garifuna Territory. PoLAR: Political and Legal Anthropology Review, 41, 2(2018): 185-200.

Cáceres, Miguel y Zelaya, Sucelinda. Honduras. Crecimiento Económico Elitista Y Violación De Derechos Sociales. 1990-2009, 2011.

Canizales, Rolando. El fenómeno de los movimientos guerrilleros en Honduras: el caso del Movimiento Popular de Liberación Cinchonero (1980-1990). Revista Estudios, 21(2008): 93-112.

Castro Suárez, Roque. 2011. El golpe en Honduras. Ofensiva conservadora y resistencia. Bajo el volcán, 11(17).

Cunha Filho, Clayton M., André Luiz Coelho y Fidel I. Pérez Flores. A right-to-left policy switch? An analysis of the Honduran case under Manuel Zelaya. International Political Science Review, 34, 5 (2013): 519-542.

Dahl, Robert Alan. Polyarchy: Participation and opposition. New Haven: Yale University Press, 1973.

Dahl, Robert Alan. Democracy and its Critics. New Haven: Yale University Press, 1989. 
Duménil, Gérard y Dominique Lévy. Capital Resurgent: Roots of the Neoliberal Revolution. Harvard: Harvard University Press, 2004.

Edelman, Marc y León, Andrés. 2013. Cycles of Land Grabbing in Central America: An Argument for History and a Case Study in the Bajo Aguán, Honduras. Third World Quarterly, 34, 9(2013): 1697-1722.

Equipo Nizkor. Raíces Históricas De La Fortuna De Miguel Facussé Barjum, 2012. Recuperado de http://www.derechos.org/nizkor/honduras/doc/facusse.html

ERIC. Impacto socioambiental de la minería en la región noroccidental de Honduras a la luz de tres estudios de casos: Montaña de Botaderos (Aguán), Nueva Esperanza (Atlántida) y Locomapa (Yoro). El progreso: Equipo de Reflexión, Investigación y Comunicación, 2016.

Euraque, Darío. Los árabes de Honduras: Entre la inmigración, la acumulación y la política. Contribuciones árabes a las identidades iberoamericanas. K. Hauser y D. Gil., eds. Madrid: Casa Árabe, 2009.

Euraque, Darío A. Reinterpreting the Banana Republic: Region and State in Honduras, 1870-1972. Univ of North Carolina Press, 1996.

FAO. 2010. La Amenaza Hidrometeorológica En Honduras. En Tierra segura. Desastres naturales y tendencia de la tierra. Recuperado de http://www.fao.org/3/i1255b/i1255b01.pdf

Feeley, Dianne. Honduras in Context: Washington's Post-Cold War Coup. Against the Current, 25, 1 (2010): 15.

Frank, Dana. The Long Honduran Night: Resistance, Terror, and the United States in the Aftermath of the Coup. Chicago: Haymarket Books, 2018.

Fukuyama, Francis. 1989. The end of history? The national interest, 16(1989): 3-18.

Gallardo, Helio. Democratización y democracia en América Latina. Ediciones desde abajo, 2007.

Gamble, Andrew. Two Faces of Neo-liberalism. The Neoliberal Revolution: Forging the Market State. R. Robinson, ed. London: Palgrave MacMillan, 2006.

Gill, Lesley. The School of the Americas: Military Training and Political Violence in the Americas. Durham: Duke University Press, 2004.

Gonzalez, Nancie L. Solien. Sojourners of the Caribbean: Ethnogenesis and Ethnohistory of the Garifuna. Urbana: University of Illinois Press, 1988.

Gordon, Todd y Jeffery R. Webber. Canadian geopolitics in post-coup Honduras. Critical Sociology, 40, 4(2014): 601-620.

Graham, Daniel Aaron. Ghosts and Warriors: Cultural-Political Dynamics of Indigenous Resource Struggles in Western Honduras (Tesis doctoral). University of California, Berkeley, 2009. Recuperado de https://danielgrahamphd.files.wordpress.com/2011/10/grahamsuper-dissertation.pdf

Harvey, David. A brief history of neoliberalism. Oxford; New York: Oxford University Press, 2007.

Hibou, Béatrice. Privatizing the state. New York: Columbia University Press, 2004.

Holden, Robert H. Armies without nations: Public violence and state formation in Central America, 1821-1960. Oxford; New York: Oxford University Press, 2004.

Huntington, Samuel P. The third wave: Democratization in the late twentieth century. Vol. 4. Norman: University of Oklahoma press, 1993.

ICEFI. 2014. Diagnóstico de la situación minera en honduras 2007-2012. Tegucigalpa: Instituto Centroamericano de Estudios Fiscales (Icefi).

Irías, Gustavo y Sosa, Eugenio. La crisis Hondureña: percepciones ciudadanas y perspectivas para la democratización. Tegucigalpa: Centro de Estudios para la Democracia (Cespad), 2009. 
Jansen, Kees. Political Ecology, Mountain Agriculture, and Knowledge in Honduras. Amsterdam: Thela Publishers, 1998.

Kay, Cristóbal. Latin America's Agrarian Reform: Lights and Shadows'. Land Reform, Land Settlement and Cooperatives, 2(1998): 9-31.

Kinzer, Stephen. Our Man in Honduras. New York Review of Books, (2001): 40-43.

Klein, Naomi. The shock doctrine: The rise of disaster capitalism. New York: Metropolitan Books, 2007.

Lazzarato, Maurizio. The Making of the Indebted Man: An Essay on the Neoliberal Condition, trans. New York: Semiotext, 2012.

Leeson, Peter T. y Andrea M. Dean. The democratic domino theory: An empirical investigation. American Journal of Political Science, 53, 3(2009): 533-551.

Leiva de Argueta, Denia M. y Misael Castro. El estudio de las elites y los grupos de poder en Honduras. Democracia, Elites y Movimientos Sociales en Honduras. Tegucigalpa: Instituto Universitario en Democracia, Paz y Seguridad, 2010. 7-28.

Lirio, Gutiérrez Rivera. 2014. Assimilation or cultural difference? Palestinian immigrants in Honduras. Revista de Estudios Sociales, 48 (2014): 57-68.

Llanos, Mariana y Leiv Marsteintredet. Ruptura y continuidad: la caída de "Mel" Zelaya en perspectiva comparada. America Latina Hoy: Revista de Ciencias Sociales, 55(2010): 173-197.

Loperena, Christopher A. Honduras is open for business: extractivist tourism as sustainable development in the wake of disaster? Journal of Sustainable Tourism, 25, 5(2017a): 618-633.

Loperena, Christopher A. Settler Violence?: Race and Emergent Frontiers of Progress in Honduras. American Quarterly, 69, 4(2017b): 801-807.

Martí i Puig, Salvador y Diego Sánchez-Ancochea. La transformación contradictoria: democracia elitista y mercado excluyente en Centroamérica. Anuario de Estudios Centroamericanos, 40(2014): 149-171.

Middeldorp, Nick. In Honduras it is a Sin to Defend Life: An Ethnography of the Discourses, Practices and Dangers of Opposition to Mining in Honduras (Tesis de maestría). International Development Studies, Wageningen UR, Wageningen, 2014.

Middeldorp, Nick y Philippe Le Billon. Deadly Environmental Governance: Authoritarianism, Eco-populism, and the Repression of Environmental and Land Defenders. Annals of the American Association of Geographers, 109, 2(2019): 324-337.

O'donnell, Guillermo y Philippe C. Schmitter. Transitions from authoritarian rule: Tentative conclusions about uncertain democracies. John Hopkins University Press, 2013.

Pastor, Rodolfo. El ocaso de los cacicazgos: historia de la crisis del sistema político hondureño. Foro Internacional XXVI, 1 (1985): 16-30.

Perez-Brignoli, Hector. A Brief History of Central America. Berkeley: Univ of California Press, 1989.

Pérez-Sáinz, Juan Pablo. 2009. Las raíces sociales de la crisis política en Honduras. Crónica de la miseria en Intibucá. Revista Centroamericana de Ciencias Sociales, 6, 1(2009): 83-111.

Phillips, James. Honduras in Dangerous Times: Resistance and Resilience. London: Lexington Books, 2015.

Pine, Adrienne. Message control: Field notes on Washington's golpistas. NACLA Report on the Americas, 43, 2(2010): 18-22. 
Pirker, Kristina y Omar Núñez. Cuatro hipótesis y un corolario en torno al golpe de estado en Honduras. OSAL XI, 28(2010): 119-43.

Posas, Mario. El Movimiento Campesino Hondureño: Una Perspectiva General. Vol. 2. Tegucigalpa: Editorial Guaymuras, 1981.

Purper, Benjamin Richard. Ideas versus Interests: US Foreign Policy and the Honduras Coup of 2009, 2017.

Ríos, Gilberto. Capitalismo, Tierra Y Poder En Honduras. Capitalismo: Tierra Y Poder En América Latina (1982-2012). G. Almeyra, L. C. Bórquez, J. M. M. Pereira, y C. Walter, eds. México: CLACSO, 2014. 147-180.

Robinson, William I. Promoting polyarchy: Globalization, US intervention, and hegemony. Cambridge: Cambridge University Press, 1996.

Robinson, William I. Transnational Conflicts: Central America, Social Change and Globalization. New York: Verso, 2003.

Rose, Nikolas, Pat O'Malley, y Mariana Valverde. 2012. Gubernamentalidad. Astrolabio, 8(2012).

Ruhl, J. Mark. Honduras Unravels. Journal of Democracy, 21, 2(2010): 93-107.

Salgado, Ramón. (Ed). Crisis institucional y golpe de estado en Honduras. Tegucigalpa: Universidad Pedagógica Nacional Francisco Morazán, 2010.

Salomón, Leticia. 2009. Políticos, empresarios y militares: protagonistas de un golpe anunciado. Alainet, 2009. Recuperado de https://www.alainet.org/es/active/31381

Segovia, Alexander. Centroamérica después del café: el fin del modelo agroexportador tradicional y el surgimiento de un nuevo modelo. Revista Centroamericana de Ciencias Sociales, 1, 2(2004): 7-38.

Shipley, Tyler. Genealogy of a social movement: the Resistencia in Honduras. Canadian Journal of Latin American and Caribbean Studies, 41, 3(2016): 348-365.

Shipley, Tyler. Ottawa and empire: Canada and the military coup in Honduras. Toronto: Between the Lines, 2017.

Soler, Lorena. Golpes de Estado en el siglo XXI. Un ejercicio comparado Haití (2004), Honduras (2009) y Paraguay (2012). Cadernos Prolam/USP, 14, 26(2015): 77-89.

Sosa, Eugenio. Democracia y movimientos sociales en Honduras: de la transición política a la ciudadania indignada. Tegucigalpa: Editorial Guaymuras, 2016.

Taylor-Robinson, Michelle M. La política hondureña y las elecciones de 2005. Revista de ciencia politica (Santiago), 26, 1(2006): 114-124.

Thiesenhusen, William C. Broken Promises: Agrarian Reform and the Latin American Campesino. New York: Westview Press, Inc, 1995.

Torres-Rivas, Edelberto. Interpretación Del Desarrollo Social Centroamericano: Procesos Y Estructuras De Una Sociedad Dependiente. San José: Editorial Universitaria Centroamericana, 1981.

Treminio Sánchez, Ilka. Las reformas a la reelección presidencial del nuevo siglo en América Central: tres intentos de reforma y un golpe de Estado. Política y gobierno, 22, 1(2015): 147-173.

Vitullo, Gabriel E. Transitologia, consolidologia e democracia na américa latina: uma revisão crítica. Revista de Sociologia e Política, 17(2001): 53-60.

Williams, Robert Gregory. States and Social Evolution: Coffee and the Rise of National Governments in Central America. Chapel Hill: UNC Press Books, 1994.

Wrathall, David J. Migration amidst social-ecological regime shift: The search for stability in Garifuna villages of northern Honduras. Human Ecology, 40, 4(2012): 583-596. 
Génesis Guzmán Padilla. Costarricense. Estudiante de Ciencias Políticas de la Universidad de Costa Rica.

Contacto: genesis.guzman@ucr.ac.cr

ORCID: 0000-0002-4762-8482

Andrés León Araya. Costarricense. Doctor en Antropología por la Universidad de la Ciudad de Nueva York, EE. UU. Actualmente director del Centro de Investigaciones y Estudios Políticos (CIEP) de la Universidad de Costa Rica.

Contacto: andres.leon_a@ucr.ac.cr

ORCID: 0000-0002-1594-5184 